\title{
Hypoxia promotes pancreatic cancer cell migration, invasion, and epithelial-mesenchymal transition via modulating the FOXO3a/ DUSP6/ERK axis
}

\author{
Hua Zhao ${ }^{1}$, Wei Chen ${ }^{2}$, Yi Zhu ${ }^{1}$, Jianying Lou ${ }^{1}$ \\ ${ }^{1}$ The Second Affiliated Hospital, Zhejiang University School of Medicine, Zhejiang University, Hangzhou, China; ${ }^{2}$ The First Affiliated Hospital, \\ Zhejiang University School of Medicine, Zhejiang University, Hangzhou, China \\ Contributions: (I) Conception and design: J Lou; (II) Administrative support: None; (III) Provision of study materials or patients: None; (IV) \\ Collection and assembly of data: H Zhao, J Lou, W Chen; (V) Data analysis and interpretation: H Zhao, J Lou; (VI) Manuscript writing: All authors; \\ (VII) Final approval of manuscript: All authors. \\ Correspondence to: Jianying Lou. The Second Affiliated Hospital, Zhejiang University School of Medicine, Zhejiang University, 88 Jiefang Road, \\ Hangzhou 310009, China. Email: loujianying@zju.edu.cn.
}

Background: Pancreatic cancer (PC) is among the most aggressive types of cancer. Hypoxia has been identified as a key risk factor for cancer progression. The forkhead box (FOX) proteins are multidirectional transcriptional factors that are strongly implicated in malignancies. However, whether FOXO3a, a member of the FOX protein family, is involved in the pro-oncogenic functions of hypoxia in PC has remained largely unelucidated. In this study, we attempted to clarify the role of FOXO3a in metastasis under hypoxic conditions and its underlying mechanism.

Methods: MTT and flow cytometry assays were performed to detect the cell proliferation and cell cycle distribution respectively. Transwell assays were used to determine the potential of cell migration and invasion. qPCR and western blot assays were used to assess the expression of mRNA and protein. Immunofluorescence assay was performed to evaluate the cellular localization of FOXO3a. FOXO3a overexpression plasmid was constructed to perform the rescue experiment.

Results: Our data indicated that PANC-1 and SW1990 cells represented enhanced cell migration and invasion abilities under hypoxia, while no statistical differences in cell proliferation and cell cycle distribution were observed. Hypoxia upregulated the messenger RNA (mRNA) and protein expressions of HIF-1 $\alpha$, FOXO3a, and the key epithelial-mesenchymal transition (EMT)-related (EMT) molecules N-cadherin and vimentin, as well as the phosphorylation of FOXO3a. Interestingly, hypoxia promoted the extranuclear localization of FOXO3a. Overexpression of FOXO3a not only significantly decreased the invasion, migration, and EMT of PC cell lines, but also reversed hypoxia-induced extranuclear localization. Finally, FOXO3 a might act as a tumor suppressor in PC by inhibiting the ERK signaling pathway by inducing DUSP6 expression, and the ERK activator fisetin could effectively attenuate the inhibitory role of FOXO3a on ERK.

Conclusions: Taken together, our results identified that hypoxia-induced extranuclear localization of FOXO3a promoted cell migration and invasion of human PC by modulating the DUSP6/ERK pathway.

Keywords: Pancreatic cancer (PC); hypoxia; forkhead box O3a (FOXO3a); metastasis; ERK signaling pathway

Submitted Jun 09, 2021. Accepted for publication Jul 22, 2021.

doi: 10.21037/jgo-21-359

View this article at: https://dx.doi.org/10.21037/jgo-21-359 


\section{Introduction}

Pancreatic cancer (PC) is a major mortal gastrointestinal cancer, and its incidence rate was still very high in China $(1,2)$. Elementary treatment options for PC patients include surgical or chemoradiotherapy schemes (3). Although these strategies are efficacious, the 5 -year survival rate is only $4 \%$ due to the drug resistance and metastasis (4). Therefore, new therapeutic targets for PC are urgently needed.

FOXO proteins are a subpopulation of the forkhead box (FOX) family and belong to polydirectional transcriptional factors that regulate many biological procedures, including cell proliferation, metabolism, and survival (5-7). The FOXO proteins, particularly FOXO3a, usually act as tumor suppressors by regulating cell cycle arrest and cell metastasis via inactivation by some critical oncogenic signaling pathways, such as the PI3K/AKT and MAPK/ERK pathways (8-10). In multiple cancer cells, the abnormal activation of PI3K/AKT pathway leads to the devitalization of FOXO proteins, which promotes the development of chemoresistance and tumor metastasis (11-13).

Hypoxia is one of the leading risk factors for cancer progression. It induces the expression of HIF $1 \alpha$ and its downstream target genes which take part in regulation of tumor metastasis, angiogenesis, immune evasion, and resistance to chemotherapy and radiation therapy in multiple cancer types including PC $(14,15)$. Dozens of studies have indicated that hypoxia could regulate $\mathrm{FOXO}$ a expression and activation. For example, FOXO3a was activated and its nuclear localization was also enhanced in a hypoxia-inducing cell or tissue injury model (16). In hepatocellular carcinoma, hypoxia positively regulates sorafenib resistance by inducing autophagy via the activation of FOXO3a (17). However, the function of FOXO3a and its activation in hypoxia-inducing cancer cell migration and invasion in cancers including PC is poorly understood.

In the present study, we observed that the migration and invasion potential of PANC-1 and SW1990 were heightened under hypoxic conditions. Hypoxia inactivated FOXO3a by promoting its phosphorylation and extranuclear localization via activation of the AKT signaling pathway. Over-expression of $\mathrm{FOXO} 3 \mathrm{a}$ decreased the cell invasion and migration potential of PC cells, and reversed hypoxia-inducing extranuclear localization. The ectopic expression of FOXO3a increased DUSP6 expression and effectively inhibited the phosphorylation of ERK in PANC-1 cells. By activating ERK using the agonist fiestin, the roles of FOXO3a on ERK cell migration and invasion were effectively attenuated. In summary, the results manifested that hypoxia-induced
FOXO3a inactivation promotes cell migration and invasion of human PC by ERK signaling pathways.

We present the following article in accordance with the MDAR reporting checklist (available at https://dx.doi. org/10.21037/jgo-21-359).

\section{Methods}

\section{Cell culture and bypoxia treatment}

Two human PC cell lines PANC-1 (CRL-1469) and SW1990 (CRL-2172) used in this study were obtained from the American Type Culture Collection (ATCC, Manassas, VA, USA) and all cells were cultured in Dulbecco's modified eagle medium (DMEM; Thermo Fisher Scientific, Inc., Waltham, MA, USA) with $10 \%$ fetal bovine serum (FBS; Cytiva, Marlborough, MA, USA), $100 \mu \mathrm{g} / \mathrm{mL}$ streptomycin, and $100 \mathrm{U} / \mathrm{mL}$ penicillin. All cells were maintained in a humidified incubator at $37^{\circ} \mathrm{C}$ with $5 \% \mathrm{CO}_{2}$.

For hypoxia treatment, cells were cultured in a trigas incubator (Thermo Fisher Scientific, Inc.) with 1\% oxygen and the best incubation time for each cell line was determined using transwell assay in which the cell migration was promoted.

\section{Western blotting}

Cells were lysed in lysis buffer containing $1 \mathrm{mM}$ phenylmethylsulfonyl fluoride (PMSF), 1\% Triton X 100, $4.9 \mathrm{mM} \mathrm{MgCl}, 1 \mathrm{mM}$ orthovanadate, $2.1 \mu \mathrm{g} / \mathrm{mL}$ aprotinin, and $0.5 \mu \mathrm{g} / \mathrm{mL}$ leupeptin. After separation using $12 \%$ sodium dodecyl sulfate-polyacrylamide gel electrophoresis (SDS-PAGE), proteins were transferred onto polyvinylidene difluoride (PVDF) membranes. Then, membranes were blocked with $5 \%$ fat-free milk for $2 \mathrm{~h}$ at room temperature followed by incubation with primary antibodies against HIF $1 \alpha$ (CST, No. 36169), FOXO3a (CST, No. 12829), p-FOXO3a (CST, No. 9466), N-cadherin (CST, No. 13116), vimentin (CST, No. 5741), ERK (CST, No. 9102), p-ERK (CST, No. 4370), AKT (CST, No. 4685), and p-AKT (CST, No. 4060), and antibodies against DUSP5 (Abcam, No. 200708) and DUSP6 (Abcam, No. 76310) at $4{ }^{\circ} \mathrm{C}$ overnight. Finally, membranes were incubated with the horseradish peroxidase (HRP)-conjugated secondary antibody at room temperature for at least $1 \mathrm{~h}$. After chemiluminescence reaction with HRP substrate, X-ray film (Fujifilm, Minato, Tokyo, Japan) were used to visualized the signal. We used $\beta$-Actin as the loading control. 


\section{Cell viability assay}

MTT assay was performed to determine the cell viability in 96-well plates of PC cell lines using the agent 3-(4,5-dimethylthiazol-2-yl)-2,5-diphenyl tetrazolium bromide. In brief, after hypoxia treatment for the indicated time, the cells were seeded at a density of 5,000 cells/well and allowed to incubate in normoxic conditions for 24-96 h. Next, the cells were subjected to MTT assay to determine cell survival rates. The $570 \mathrm{~nm}$ absorbance value of each sample was read by a microplate reader (Molecular Devices, San Jose, CA, USA).

\section{Cell cycle assay by flow cytometry}

Flow cytometry experiment was used to determine the cell cycle distribution using propidium iodide (PI) staining. In brief, cells were seeded into a $6 \mathrm{~cm}$ dish at $1 \times 10^{5}$ cells/dish and incubated overnight to allow cell attachment. After cells were treated with hypoxia for the indicated time, they were harvested, washed with phosphate-buffered saline (PBS), and fixed in $75 \%$ ethanol at $4{ }^{\circ} \mathrm{C}$ for at least $8 \mathrm{~h}$. Then, the fixed cells were incubated with RNase A $(100 \mu \mathrm{g} / \mathrm{mL})$ and $0.1 \%$ TritonX-100 for $30 \mathrm{~min}$ at $37^{\circ} \mathrm{C}$. After that, cells were stained with PI $(30 \mu \mathrm{g} / \mathrm{mL})$ and detected by flow cytometry (FACS Calibur, Becton, Dickinson and Co., (BD) Biosciences, Franklin Lakes, NJ, USA). The FlowJo software program (Flowjo, LLC, Ashland, OR, USA) was used to analyze the percentages of cells at G1, S, and G2/M were calculated by based on their DNA content.

\section{In vitro migration and invasion assays}

To determine the cell migration, the transwell assay was performed using a chamber $(8 \mu M$ pore; Corning Life Sciences, Tewksbury, MA, USA) according to the manufacturer's instruction. After cells were suspend in serum-free DMEM, they were seeded into the upper Transwell chambers. The lower compartment was placed into 24-well plates which was filled with DMEM with $10 \% \mathrm{FBS}$ as a chemoattractant. After $24 \mathrm{~h}$ incubation, iced methanol was used to fix the cells and then cells were stained with $0.5 \%$ crystal violet solution for $30 \mathrm{~min}$ at room temperature. After removing the cells remaining in the upper surface of chamber, the number of cells migrated to the lower side were counted by a microscope (Olympus Corporation, Shinjuku, Tokyo, Japan) at $\times 200$ magnification. For invasion assays, Transwells were pre- coated with Matrigel (BD Biosciences, USA) before the cells were added. The following steps were the same as those in the migration assay.

\section{Immunofluorescence microscopy for FOXO3 a detection}

The PANC-1 cells were seeded in 6-well plates and incubated under normoxic or hypoxic conditions for $24 \mathrm{~h}$. The immunofluorescence staining experiment was performed according to the manufacturer's instructions. Briefly, $4 \%$ formaldehyde was used to fix PANC-1 cells at room temperature for $30 \mathrm{~min}$. We then used icecold absolute methanol to permeabilize the cells at room temperature for $10 \mathrm{~min}$. After blocking by incubation with PBS containing 3\% bovine serum albumin (BSA) at room temperature for $30 \mathrm{~min}$, cells were incubated with anti-FOXO3a antibody in blocking buffer for $2 \mathrm{~h}$ at room temperature followed by incubation with goat anti rabbit antibody conjugated with Alexa Fluor 594 (Cell Signaling Technology, Danvers, MA, USA) for $1 \mathrm{~h}$ at room temperature, and nuclei were stained with $1 \mu \mathrm{g} / \mathrm{mL}$ DAPI in PBS. Images were taken with a fluorescent microscope (Olympus Corporation, Japan).

\section{Plasmid construction and transfection}

The coding sequence (CDS) of human FOXO3a mRNA were synthesized and digested using restriction enzymes HindIII and EcoRI. After that, the DNA fragment was subcloned into the empty pcDNA3.1 vector to construct the FOXO3a overexpression plasmid. DNA sequencing was used to confirm the integrity of the plasmid constructed. The transfection complex was prepared with Lipofectamine ${ }^{\circledR} 3000$ (Thermo Fisher Scientific, Inc., USA) for $20 \mathrm{~min}$ at room temperature according to the manufacturer's instructions, and transfection was carried out at $37^{\circ} \mathrm{C}$ for $24 \mathrm{~h}$. Western blot assay was performed to determine the expression efficiency of pcDNA3.1-FOXO3a plasmid transfection.

\section{Statistical analysis}

All numerical data were presented as the means \pm standard deviation (SD). GraphPad Prism 5.0 (GraphPad Software, Inc., La Jolla, CA, USA) and SPSS 13.0 (SPSS, Inc., Chicago, IL, USA) software packages were used for all statistical analyses. 2-sided Student's $t$-test was used to determine the statistical significance, and p-values below 

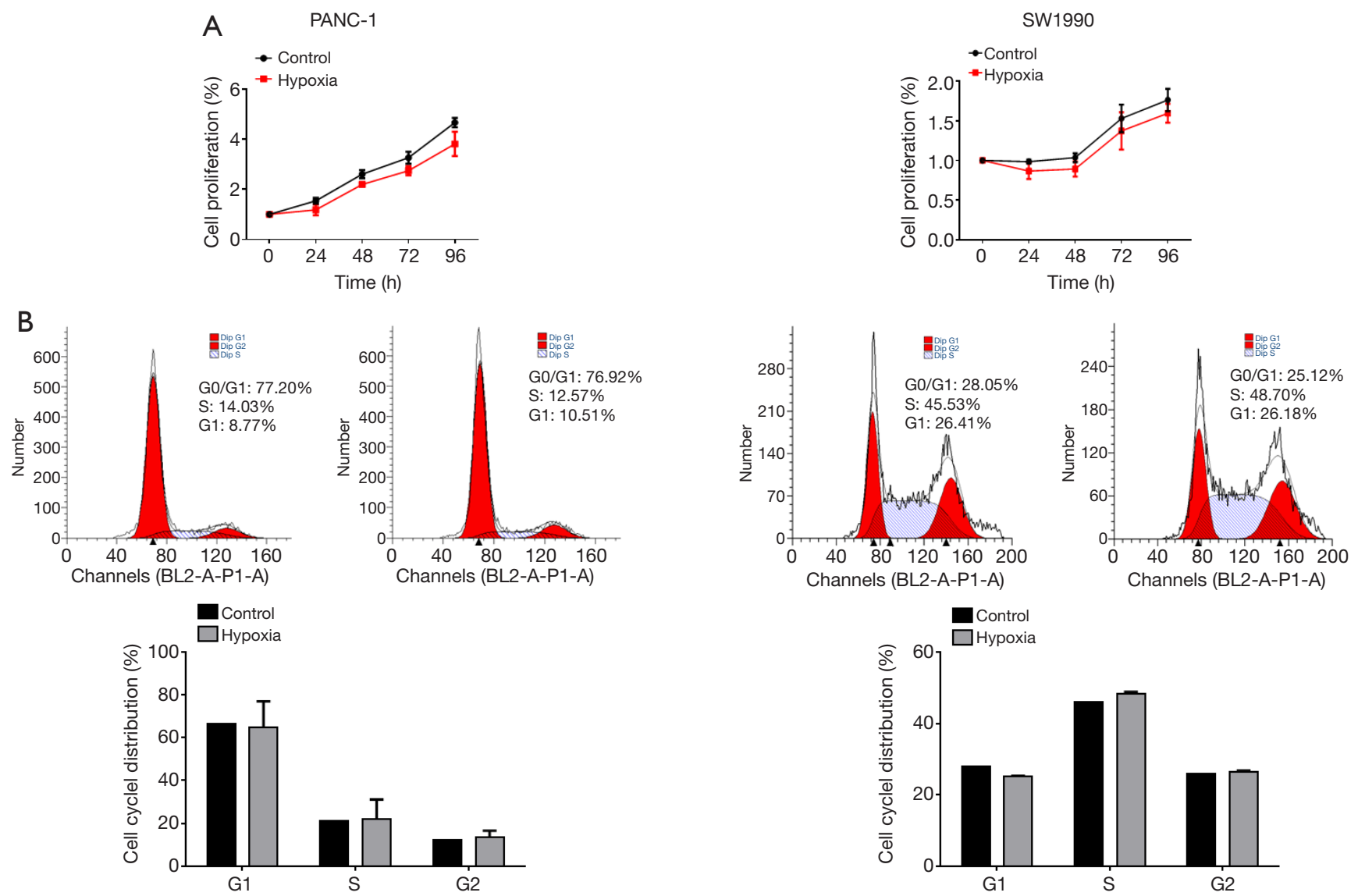

Figure 1 Hypoxia weakly inhibited cell proliferation of PANC-1 and SW1990 cells. (A) Cells were cultured under normoxic or hypoxic conditions for the indicated time (24 h for PANC-1 and $4 \mathrm{~h}$ for SW1900 cells), and then, 2 cell lines were seeded in 96-well plates for culturing under normoxic conditions for 24-96 h. MTT assay was performed to determine cell viability. (B) Cell cycle distribution of PANC-1 and SW1990 cells under normoxic or hypoxic conditions were detected by flow cytometry, and representative photographs are presented. Quantitative analysis of cell cycle distribution is shown in the histogram. MTT, 3-(4,5-dimethylthiazol-2-yl)-2,5-diphenyl tetrazolium bromide.

0.05 were considered statistically significant.

\section{Results}

\section{Hypoxia exerted a weak inbibitory function on cell proliferation in PC cells}

To investigate the mechanism of pro-oncogenic effects of a hypoxic condition on PC, 2 cell lines PANC- 1 and SW1990 were used. Firstly, the cell viability of PANC-1 and SW1990 cells under normoxic or hypoxic conditions $\left(1 \% \mathrm{O}_{2}\right)$ were detected by MTT assay at the indicated time points. As shown in Figure 1A, although hypoxia exerted a weak inhibitory effect on cell proliferation, both PC cell lines showed no statistical difference on cell proliferation under hypoxic conditions compared with normoxic ones.

To further confirm the results of MTT assay, PC cell lines were collected and flow cytometry was performed to analyze cell cycle distribution. As illustrated in Figure $1 B$, PANC-1 and SW1990 cells in the hypoxic group had no significant difference in cell cycle distribution of G0/G1, S phase, and G2/M.

\section{Hypoxia significantly enhanced cell migration and invasion abilities of PC cells}

To further examine the effect of PC cell lines on tumor behavior under normoxic or hypoxic conditions, migration and invasion abilities were determined. Initially, after PANC-1 and SW1990 cells had been incubated under 
hypoxic conditions $\left(1 \% \mathrm{O}_{2}\right)$ for $24 \mathrm{~h}$ and $4 \mathrm{~h}$ respectively, the Transwell assay was performed. As shown in Figure $2 \mathrm{~A}$, hypoxia significantly promoted the cell migration and invasion potentials in both PANC-1 and SW1990 cell lines compared to those in the control group (pretreated under normoxic conditions). Furthermore, mRNA expression levels of HIF1- $\alpha$, FOXO3a, N-cadherin, and vimentin under normoxic and hypoxic conditions in PANC-1 and SW1990 cells were also tested by quantitative reverse transcription-polymerase chia reaction (RT-qPCR) assay. As shown in Figure 2B, the results showed that hypoxia significantly upregulated the expression of HIF1- $\alpha$, FOXO3a, N-cadherin, and vimentin mRNAs.

\section{Hypoxia promoted EMT and inactivated FOXO3a in PC cells}

Next, the protein expression of HIF- $\alpha$, FOXO3a, as well as mesenchymal markers $\mathrm{N}$-cadherin and vimentin of $\mathrm{PC}$ cells under hypoxic conditions were determined by western blotting assay. As shown in Figure 3A, our data indicated that the protein expressions of HIF- $\alpha$ and FOXO3a in PC cell lines PANC-1 and SW1990 were dramatically upregulated under hypoxic conditions. Furthermore, the expressions of $\mathrm{N}$-cadherin and vimentin in PANC-1 and SW1990 cell lines under hypoxic conditions were also significantly elevated (Figure $3 A$ ). Interestingly, hypoxia also promoted the phosphorylation of FOXO3a, which suggested that FOXO3a had been inactivated (Figure $3 A$ ). Finally, using immunofluorescence microscopy technology, we found that hypoxia induced FOXO3a extranuclear localization imaged by overlapping red fluorescence conjugated FOXO3a and nuclei stained with DAPI in PANC-1 cells (Figure 3B).

\section{FOXO3a overexpression impaired bypoxia-promoted PC cell migration and invasion}

To study the biological role of FOXO3a in cell migration and invasion of $\mathrm{PC}$ cells under hypoxia, a FOXO3 a overexpression plasmid was constructed. After PANC1 and SW1990 cells had been transfected with the pcDNA3.1 vector or FOXO3a overexpression plasmid, the expression of FOXO3a was analyzed by western blotting. As shown in Figure 4A, FOXO3a protein levels were significantly increased in PANC-1 and SW1990 cells that had been transfected with $\mathrm{FOXO} 3$ a expression plasmid (Figure 4A). Overexpression of FOXO3a alone suppressed the cell migration and invasion potentials of PANC1 and SW1990 cells, and more importantly the ectopic expression of FOXO3a impaired the hypoxia-promoted cell migration and invasion activities in both cell lines (Figure 4B).

We employed immunofluorescence microscopy technology to further confirm the role of FOXO3a overexpression in its cellular translocation in $\mathrm{PC}$ cells under hypoxic conditions. As shown in Figure 4C, overexpression of FOXO3a not only enhanced its nucleus localization compared to the pcDNA3.1 group, but also promoted its nuclear translocation under hypoxic conditions.

\section{FOXO3 a overexpression reversed its hypoxia-promoted cell migration and invasion by inducing DUSP6}

To explore the underlying mechanisms for the role of FOXO3a in hypoxia-induced cell migration and invasion in PC, the phosphorylation of ERK, AKT, and itself was determined by western blotting assay in PANC-1 cells. As shown in Figure 5, hypoxia effectively upregulated the phosphorylation of AKT, which accounted for the phosphorylation and inactivation of FOXO3a, and our data also indicated that the ectopic expression of FOXO3a could inactivate AKT in turn (Figure 5). More interestingly, hypoxia obviously downregulated the expression of DUSP6 while FOXO3a could promote this protein. As a result, ERK was activated by hypoxia, but inactivated by FOXO3a overexpression (Figure 5). We used fisetin, an activator of ERK, to further confirm whether ERK activation was an indispensable factor for hypoxia-induced cell migration and invasion in PC cells. Our data revealed that fisetin not only promoted the phosphorylation of ERK, but also attenuated the role of FOXO3a overexpression on ERK activation (Figure 6A). More importantly, the inhibitory role of FOXO3a on cell migration and invasion was effectively reversed by fisetin (Figure 6B).

\section{Discussion}

Hypoxia is one of the main pro-oncogenic factors for regulating cancer progression (18). It may produce a multitude of changes in tumor cells, such as enhanced metastatic capability, DNA repair capacity, chemoresistance, and radioresistance (19-22). The main mediator of the biological function of hypoxia, HIF- $1 \alpha$, is a chief controller of oxygen homeostasis and can regulate multifarious cellular functions, such as cell proliferation, apoptosis, and 
A
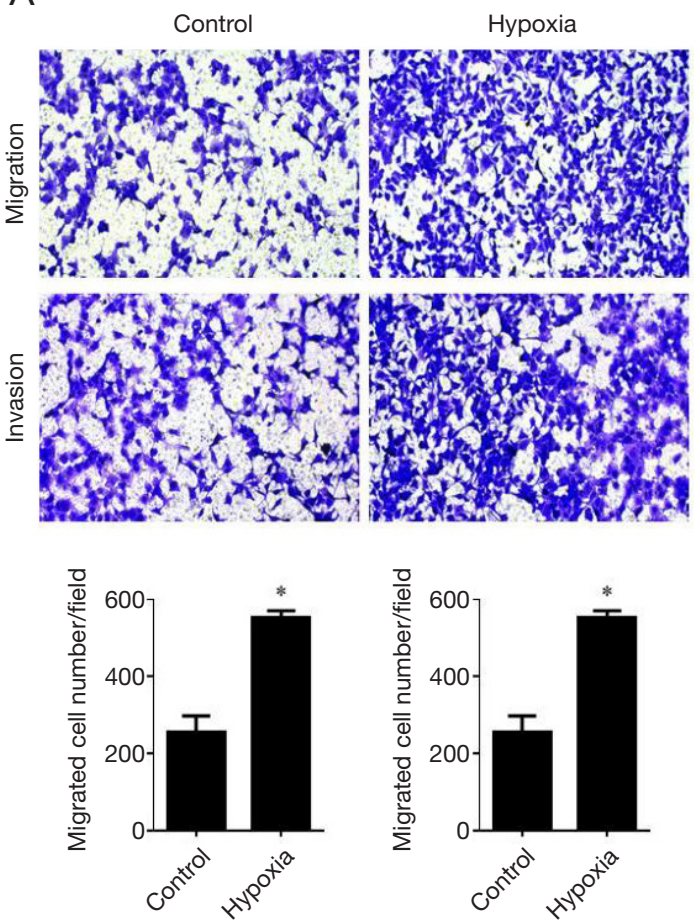

B
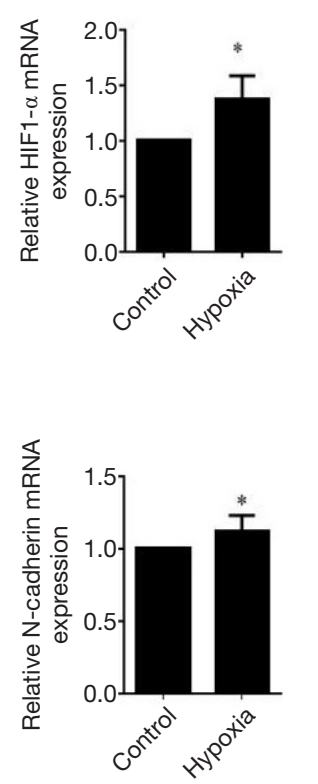
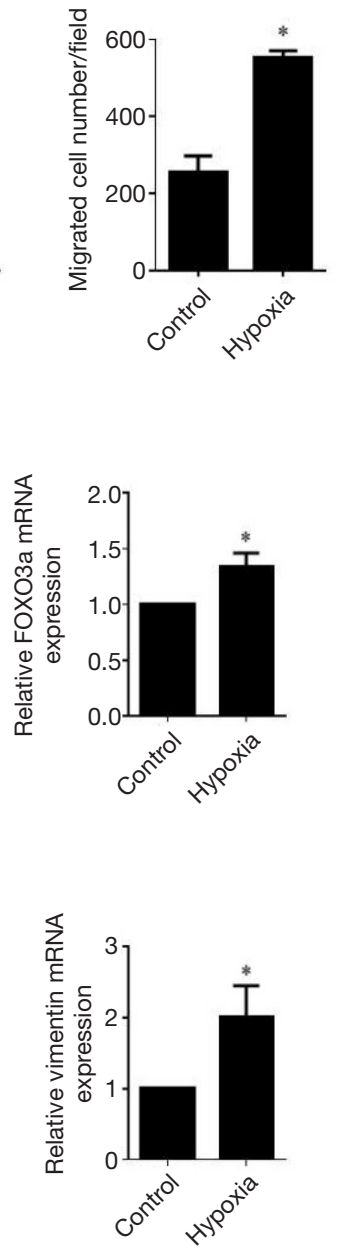
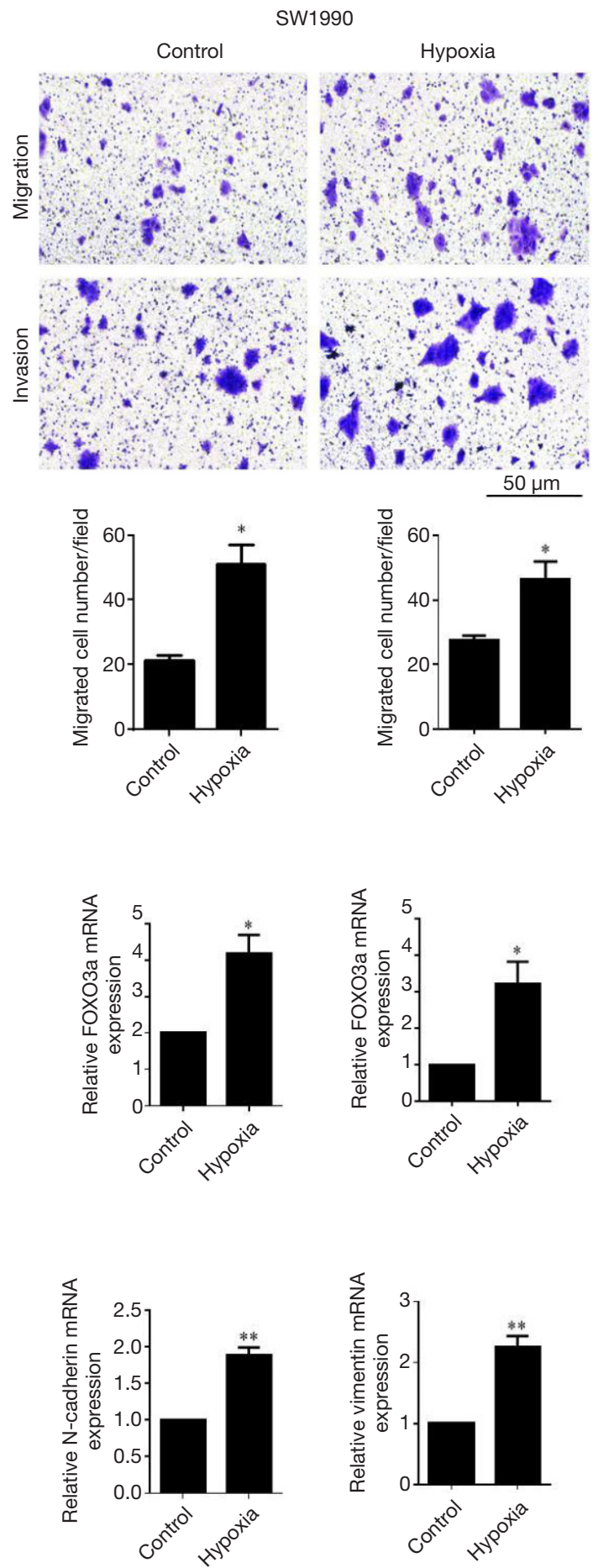

Figure 2 Hypoxia enhanced the cell migration and invasion abilities of PANC-1 and SW1990 cells. (A) PC cell lines PANC-1 and SW1990 were cultured for 24 or $4 \mathrm{~h}$, respectively, under normoxic or hypoxic conditions. Then, migration and invasion ability of PC cells were detected by Transwell assay. Cells were fixed with methanol and stained with $0.5 \%$ crystal violet solution for 30 min at room temperature. (B) Relative mRNA expression of HIF1- $\alpha$, FOXO3a, N-cadherin, and vimentin under normoxic or hypoxic conditions in PANC-1 and SW1990 tested by RT-PCR. The data are derived from three independent experiments. *, $\mathrm{P}<0.05$; ${ }^{* *}, \mathrm{P}<0.01$. PC, pancreatic cancer; RTPCR, reverse transcription-polymerase chain reaction; mRNA, messenger RNA. 


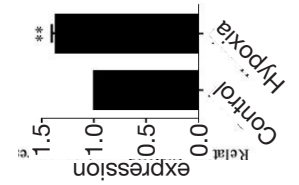

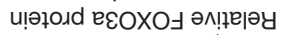

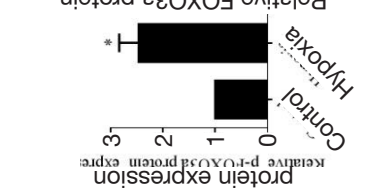

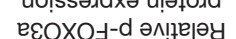
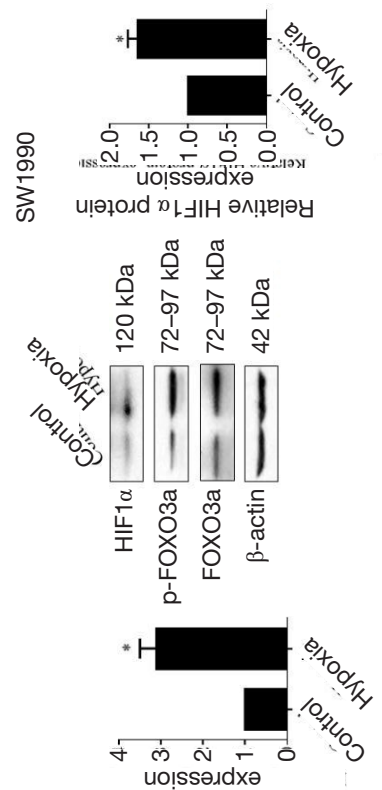

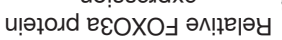

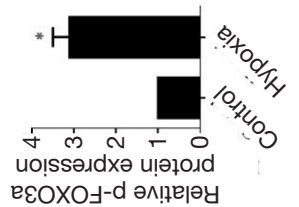

еعOXO」-d әм!ฺе|әу

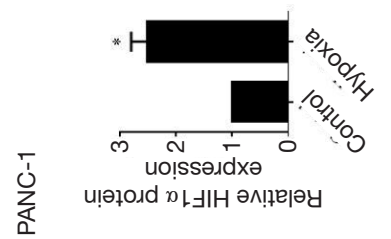

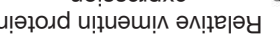
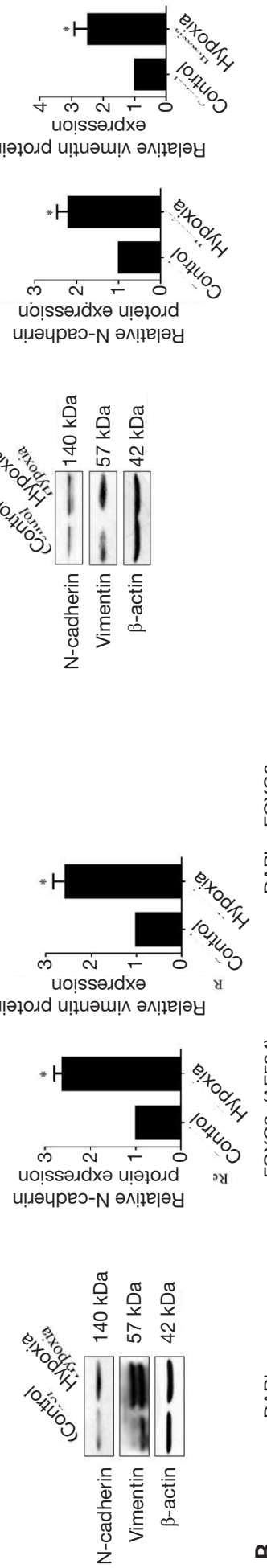

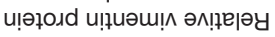
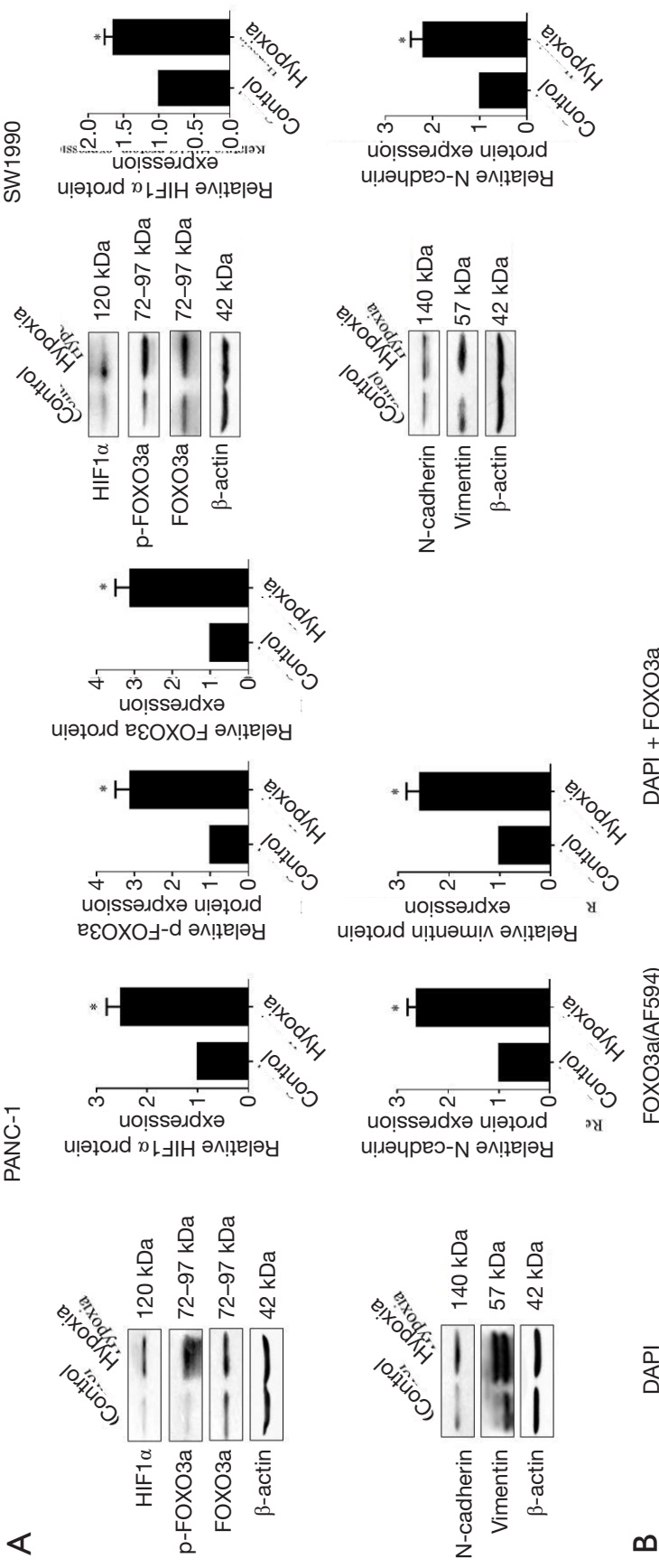
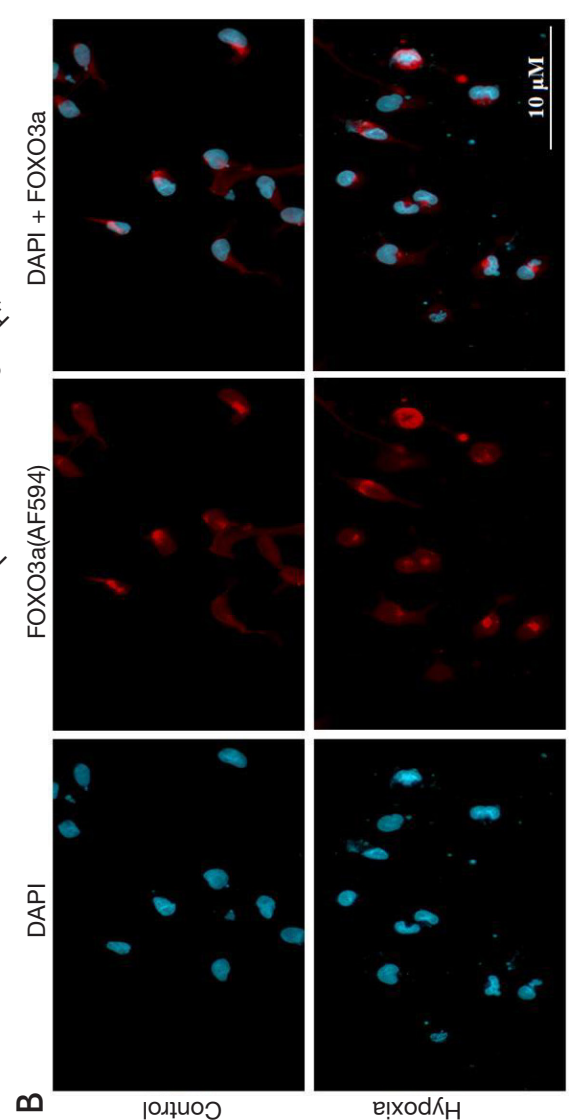

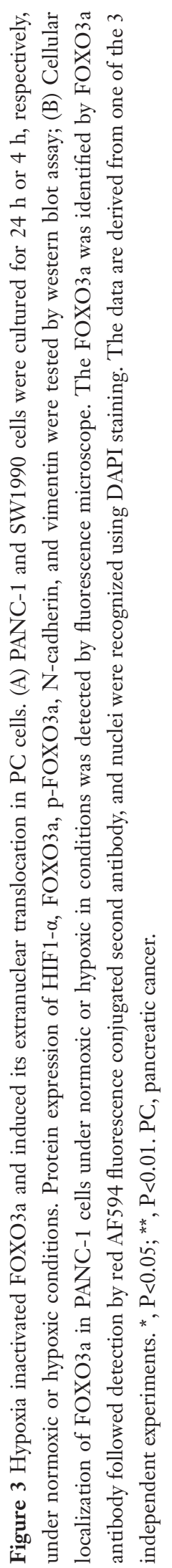



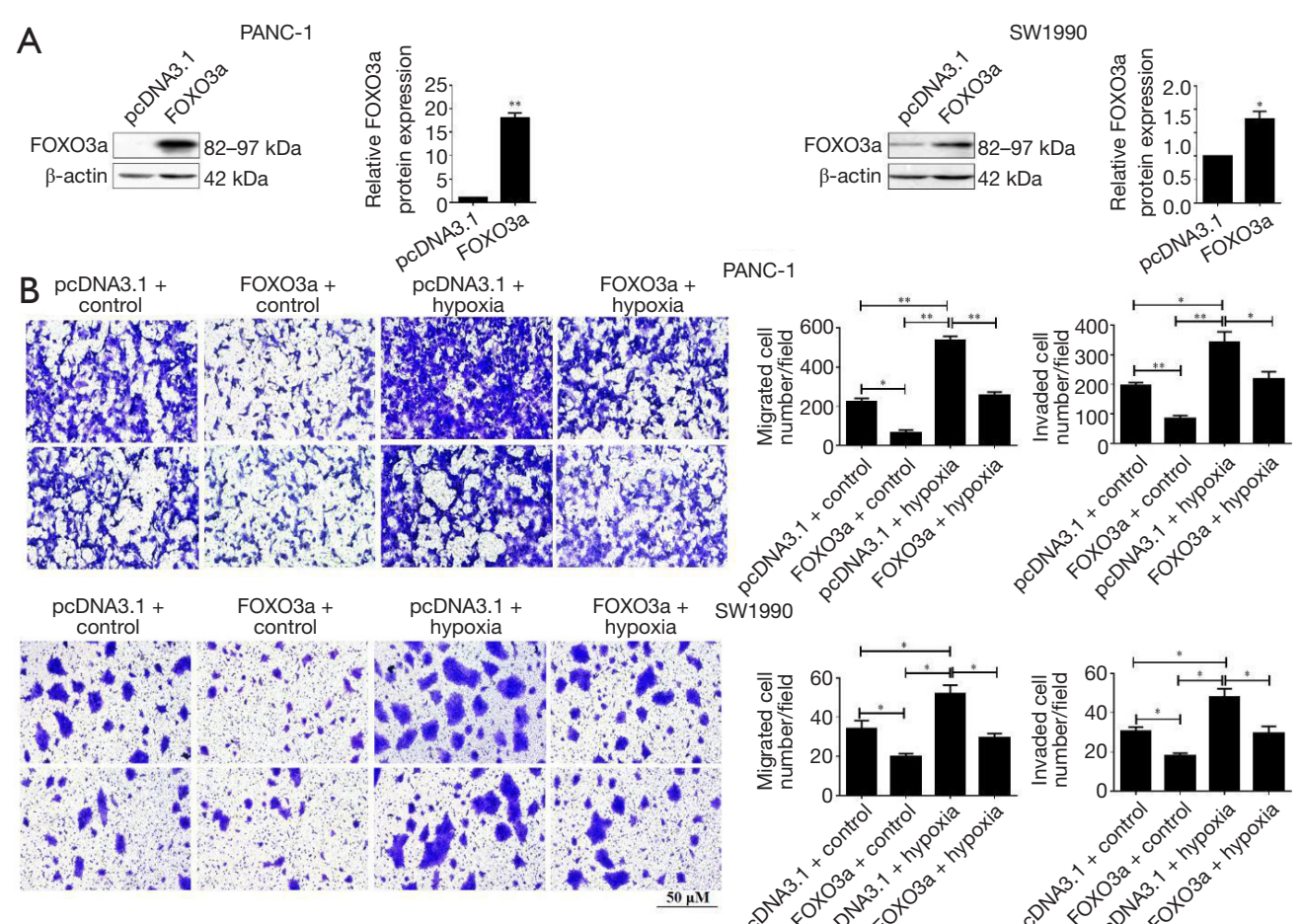

\section{C}
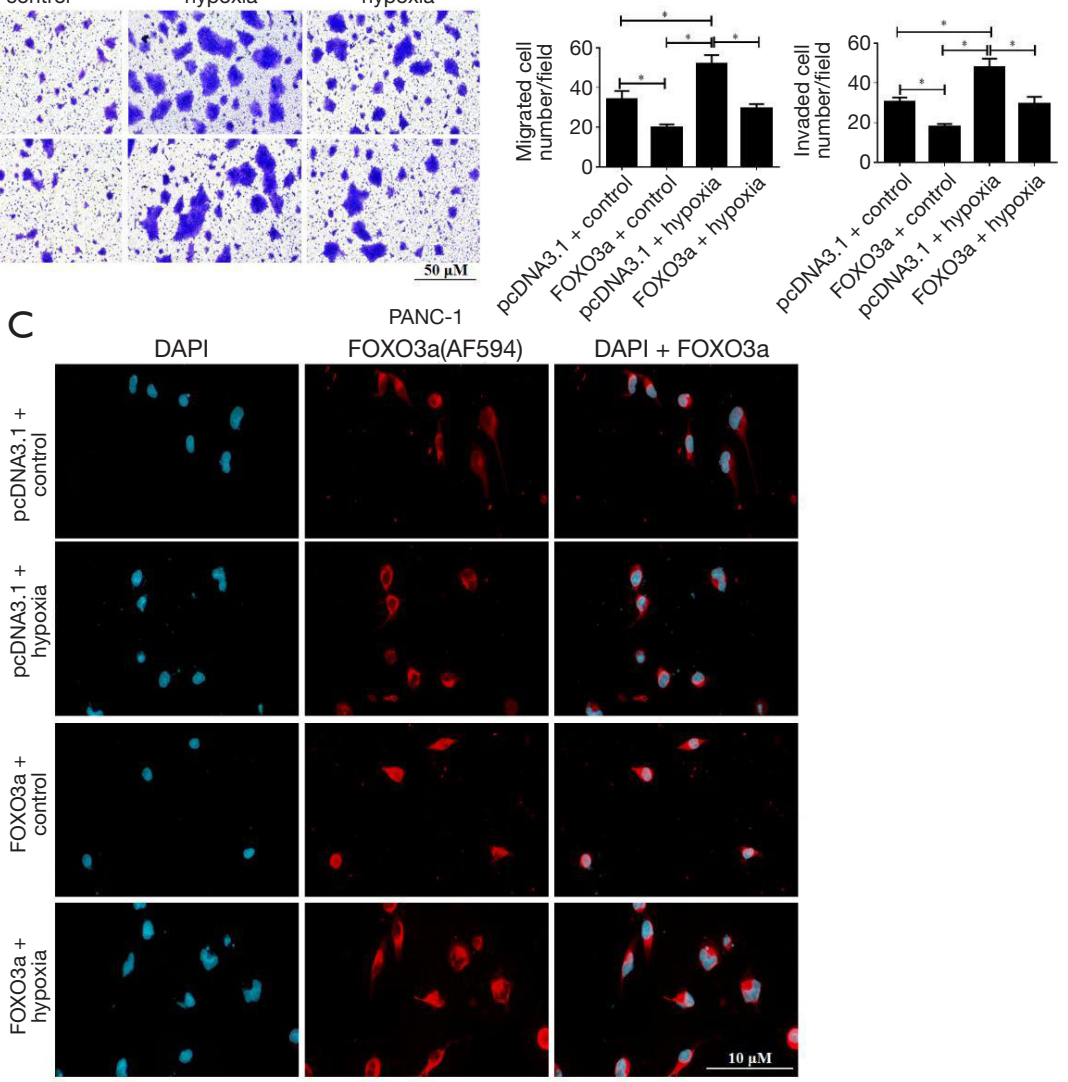

PANC-1
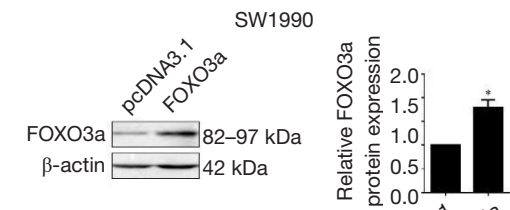

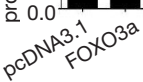
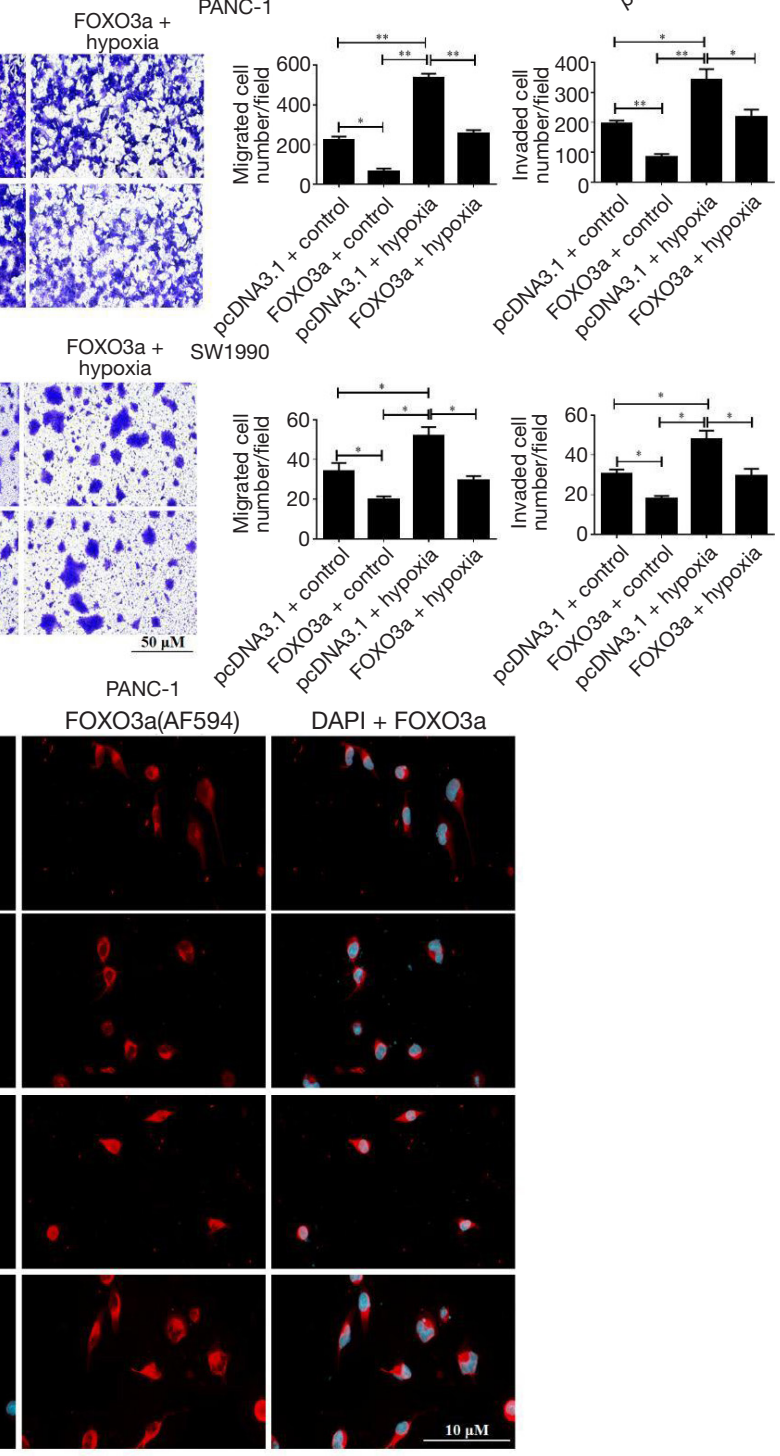

Figure 4 FOXO3a overexpression reversed PC cell migration and invasion induced by hypoxia. (A) PANC-1 and SW1990 cells were transfected with pcDNA3.1 or pcDNA-FOXO3a for $24 \mathrm{~h}$ ) and the expression of FOXO3a was confirmed by western blot assay. Quantitative analysis of FOXO3a expression is shown in the histogram. (B) PANC-1 and SW1990 cells transfected with pcDNA3.1 or pcDNA-FOXO3a for $24 \mathrm{~h}$. Cells were then cultured for another $24 \mathrm{~h}$ or $4 \mathrm{~h}$ under normoxic or hypoxic conditions. The migration and invasion ability of PC cells detected by Transwell assay. Cells were fixed with methanol and stained with $0.5 \%$ crystal violet solution for 30 min at room temperature. The data are derived from 1 of the 3 independent experiments. *, $\mathrm{P}<0.05$; ${ }^{* *}, \mathrm{P}<0.01$. (C) PANC-1 cells were transfected with pcDNA3.1 or pcDNA-FOXO3a for $24 \mathrm{~h}$. Cells were then cultured for another $24 \mathrm{~h}$ under normoxic or hypoxic conditions. Then, the cellular localization of FOXO3a was analyzed by fluorescence microscope. The FOXO3a was identified by FOXO3a antibody followed detection by red AF594 fluorescence conjugated second antibody, and nuclei were recognized using DAPI staining. Representative pictures are shown. PC, pancreatic cancer. 


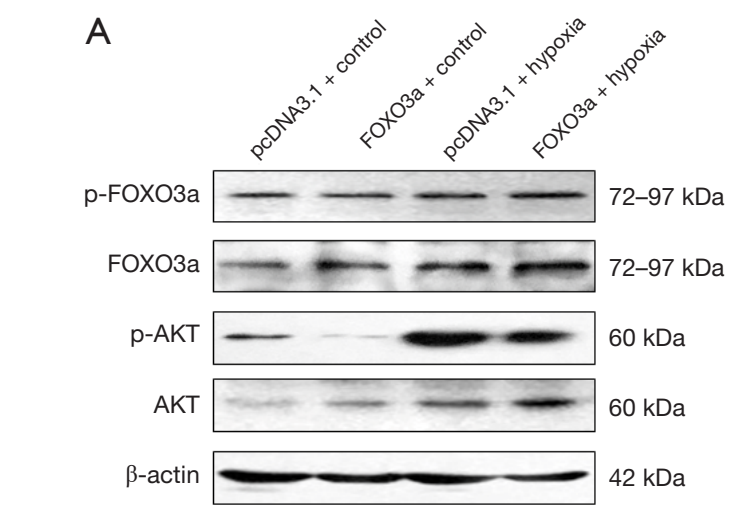

B
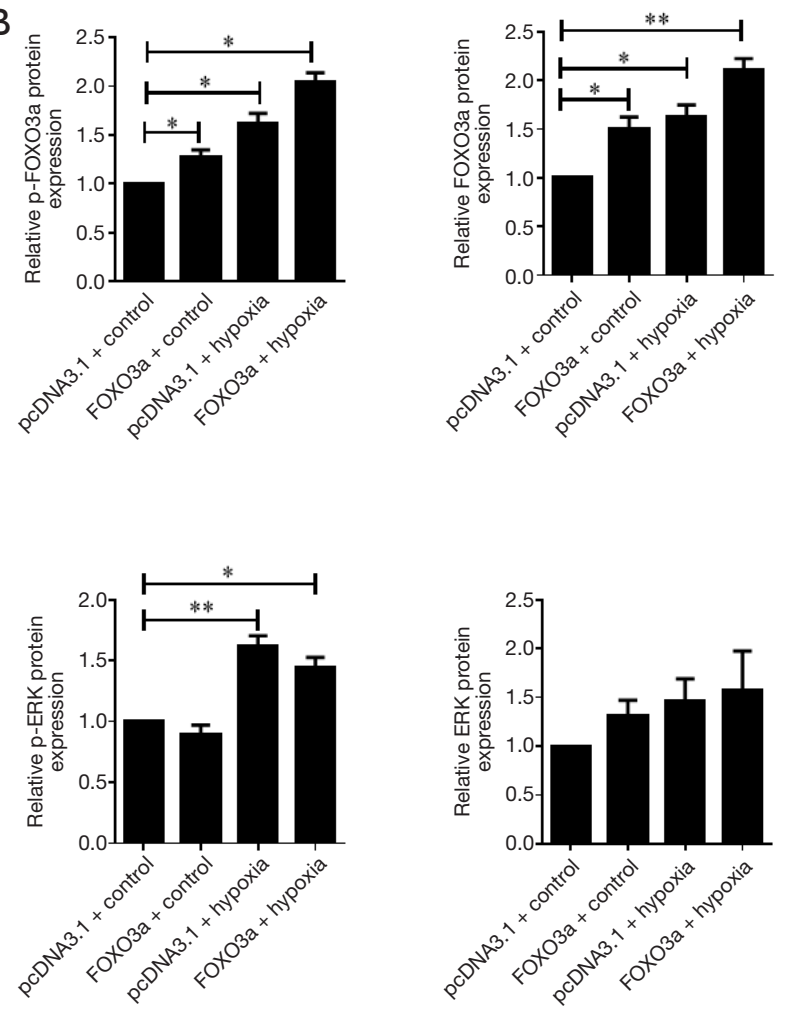
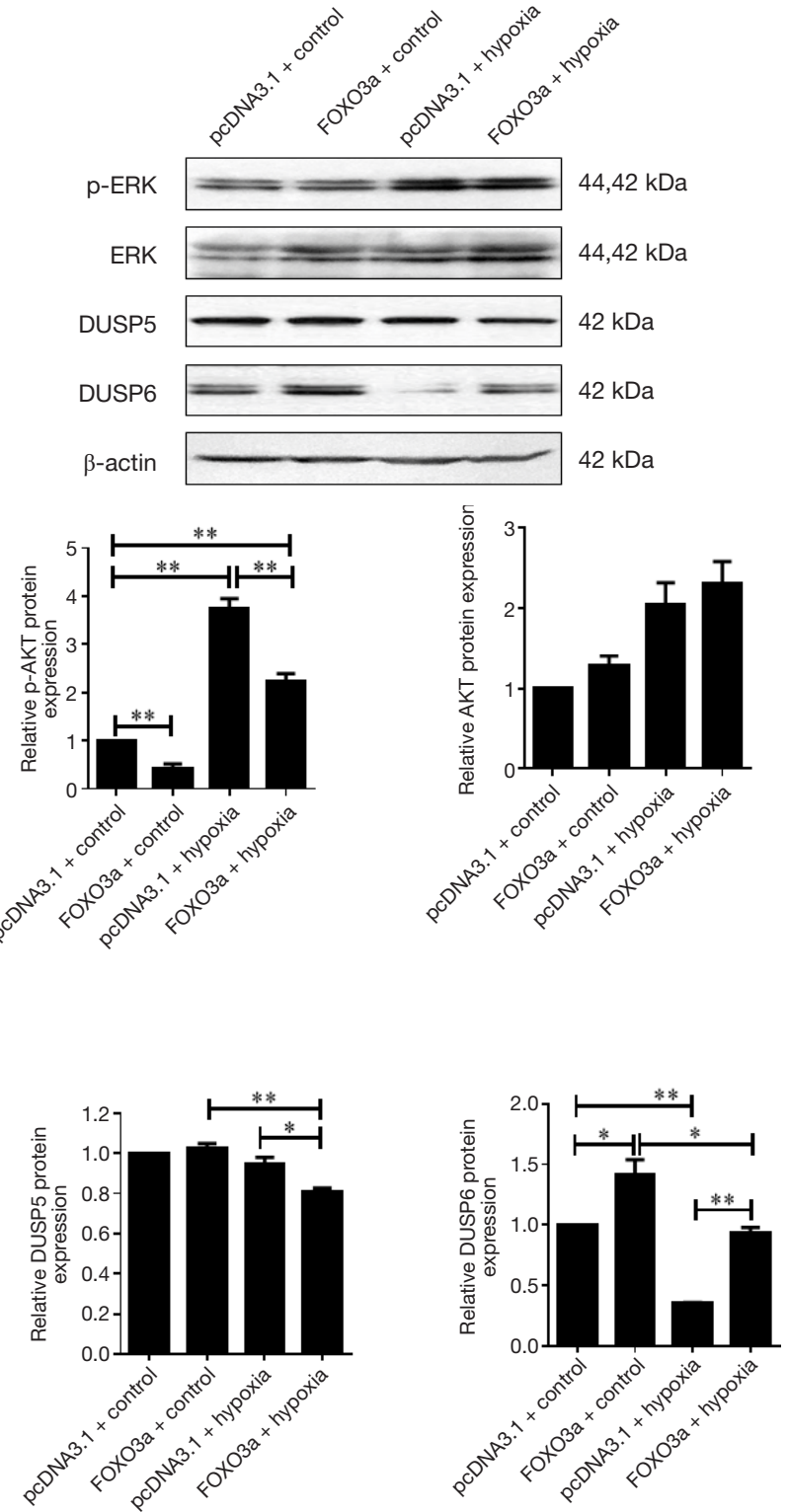

Figure 5 FOXO3a overexpression attenuated hypoxia-induced ERK activation via DUSP6. (A) PANC-1 cells transfected with pcDNA3.1 or pcDNA-FOXO3a for $24 \mathrm{~h}$ followed by another $24 \mathrm{~h}$ culture under normoxic or hypoxic conditions and analyzed by western blot for detection of the indicated proteins. Representative data from three independent experiments was shown. (B) Quantitative analysis expression of proteins in (A). Data is expressed as mean $\pm \mathrm{SD}$ for three independent experiments. ${ }^{*}, \mathrm{P}<0.05 ;{ }^{* *}, \mathrm{P}<0.01$. SD, standard deviation.

metastasis (23-25). A previous study also demonstrated that under hypoxic conditions, the enhancement in HIF$1 \alpha$ expression triggers hypoxia-mediated apoptosis by influencing the expression of downstream molecules (26). Hypoxia was also found to induce cancer metastasis by upregulated HIF-1 $\alpha$ expression via promotion of EMT (27). Multiple investigations have reported that HIF- $1 \alpha$ is potent target for the treatment of several cancer including PC. We believe that the severity and duration of hypoxia is a key factor in determining its role in cancer, especially in the cell experiment model. In the present study, we tested the role of different incubation durations of $1 \% \mathrm{O}_{2}$ in PC cells and confirmed that $24 \mathrm{~h}$ and $4 \mathrm{~h}$ of hypoxic incubation exerted the most effective promotion in PANC-1 and SW1990 cells, 

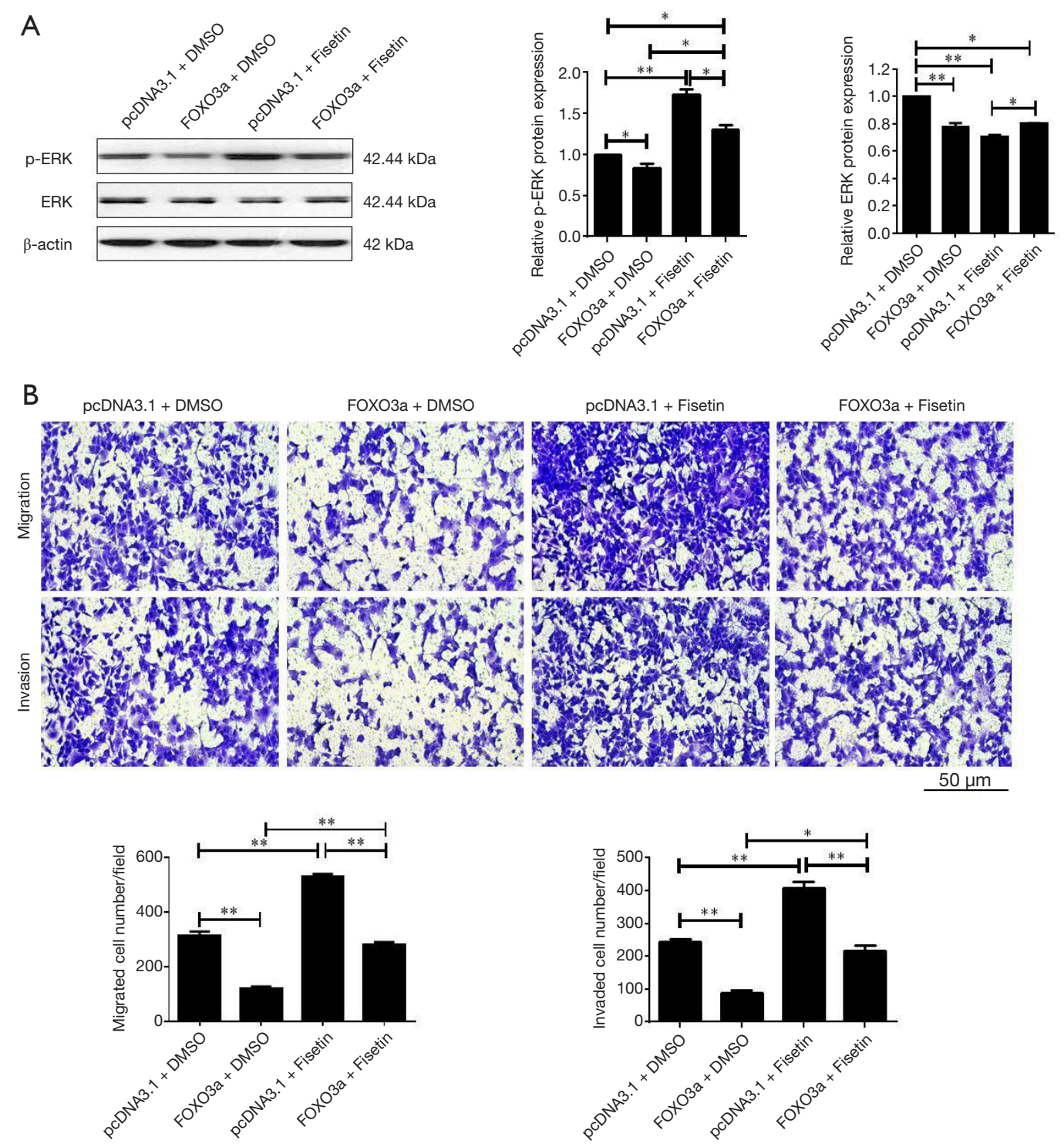

Figure 6 Fisetin reversed the roles of FOXO3a in PC cell migration and invasion by activating ERK. PANC-1 cells were transfected with pcDNA3.1 or pcDNA-FOXO3a followed by fisetin $(5 \mu \mathrm{M})$ treatment for $24 \mathrm{~h}$. (A) Western blot was performed to detect the ERK activation. Quantitative analysis of FOXO3a expression is shown in the histogram. (B) Transwell assay was performed to determine the cell migration and invasion ability. Cells were fixed with methanol and stained with $0.5 \%$ crystal violet solution for 30 min at room temperature. The data are derived from three independent experiments. * $\mathrm{P}<0.05 ;{ }^{* *}, \mathrm{P}<0.01$. PC, pancreatic cancer; DMSO, dimethlysulfoxide.

respectively. Our findings also indicated that hypoxia the induced migration and invasion of $\mathrm{PC}$ cells by promoting EMT, which was supported by the increase of $\mathrm{N}$-cadherin and vimentin expression.

The FOXO family of transcription factors are regarded as tumor suppressors that mostly regulate cell proliferation, apoptosis, cell cycle arrest, and oxidative stress (28-31). Numerous studies have reported that FOXO3a is inactivated in various cancers such as nasopharyngeal carcinoma, gastric cancer, breast cancer, hepatocellular carcinoma, ovarian cancer, lung cancer, and so on (32-37). Moreover, FOXO3a inactivation can trigger EMT and subsequently promote tumor cell migration and invasion, reflecting that FOXO3a can serve as an underlying biomarker for the prediction and treatment of tumor metastasis $(38,39)$. However, the function of FOXO3a and its activation in hypoxia-induced 
cancer cell metastasis, especially in PC, has been poorly understood.

As mentioned above, several studies have indicated that hypoxia could upregulate $\mathrm{FOXO} 3$ a expression and promote its nuclear localization in a hypoxia-induced cell or tissue injury model (16). In our hypoxia-induced PC cell migration and invasion model, hypoxia indeed increased the expression of FOXO3a, but its nuclear translocation was suppressed. In fact, we found that phosphorylation of $\mathrm{FOXO} 3 \mathrm{a}$ was upregulated under hypoxia. This finding explained why hypoxia enhanced the expression of FOXO3a but inhibited its nuclear translocation. We also detected the phosphorylation of AKT, a kinase that can phosphorylate and inactivate the FOXO3a, under hypoxic conditions. As expected, the phosphorylation of AKT was enhanced by hypoxia.

In a certain regard, the ectopic expression of FOXO3a not only effectively suppressed the migration and invasion potentials of PC cells, but also reversed the promotional role of hypoxia. Meanwhile, hypoxia-induced ERK activation could also be attenuated by FOXO3a overexpression. By screening the target genes of FOXO3a using the dataset Gene Set Enrichment Analysis (GSEA), we found DUSP5 and DUSP6 were the downstream target genes of $\mathrm{FOXO} 3 \mathrm{a}$. Interestingly, $\mathrm{FOXO} 3$ a could promote the expression of DUSP6 but not DUSP5, while hypoxia could decrease the expression of DUSP6. All these data suggested that hypoxia might promote ERK activation by inhibiting FOXO3a-induced DUSP6 expression. Finally, we used the ERK activator fisetin to further confirm ERK activation in hypoxia-induced cell migration and invasion in PC cells. As expected, fisetin not only attenuated the role of FOXO3a in ERK activation, but also promoted cell migration and invasion, even under FOXO3a overexpression.

\section{Conclusions}

In conclusion, our results suggested that hypoxia-induced inactivation of FOXO3a and decreased expression of DUSP6 promoted the cell migration and invasion of human PC cells at least partially by enhancing ERK phosphorylation.

\section{Acknowledgments}

Funding: This work was supported by funds from Medical Health Science and Technology Project of Zhejiang Provincial Health Commission (2018KY425) and the
Project of the Education Department of Zhejiang Province (Y201328151).

\section{Footnote}

Reporting Checklist: The authors have completed the MDAR reporting checklist. Available at https://dx.doi. org/10.21037/jgo-21-359

Data Sharing Statement: Available at https://dx.doi. org/10.21037/jgo-21-359

Conflicts of Interest: All authors have completed the ICMJE uniform disclosure form (available at https://dx.doi. org/10.21037/jgo-21-359). The authors have no conflicts of interest to declare.

Ethical Statement: The authors are accountable for all aspects of the work in ensuring that questions related to the accuracy or integrity of any part of the work are appropriately investigated and resolved. The study was conducted in accordance with the Declaration of Helsinki (as revised in 2013). Institutional ethical approval and informed consent were waived.

Open Access Statement: This is an Open Access article distributed in accordance with the Creative Commons Attribution-NonCommercial-NoDerivs 4.0 International License (CC BY-NC-ND 4.0), which permits the noncommercial replication and distribution of the article with the strict proviso that no changes or edits are made and the original work is properly cited (including links to both the formal publication through the relevant DOI and the license). See: https://creativecommons.org/licenses/by-nc-nd/4.0/.

\section{References}

1. Torre LA, Bray F, Siegel RL, et al. Global cancer statistics, 2012. CA Cancer J Clin 2015;65:87-108.

2. Chen $W$, Zheng R, Baade PD, et al. Cancer statistics in China, 2015. CA Cancer J Clin 2016;66:115-32.

3. Zhang Q, Li X, Li Y, et al. Expression of the PTEN/ FOXO3a/PLZF signalling pathway in pancreatic cancer and its significance in tumourigenesis and progression. Invest New Drugs 2020;38:321-8.

4. Vincent A, Herman J, Schulick R, et al. Pancreatic cancer. Lancet 2011;378:607-20.

5. Lam EW, Brosens JJ, Gomes AR, et al. Forkhead box 
proteins: tuning forks for transcriptional harmony. Nat Rev Cancer 2013;13:482-95.

6. Myatt SS, Lam EW. The emerging roles of forkhead box (Fox) proteins in cancer. Nat Rev Cancer 2007;7:847-59.

7. Coomans de Brachene A, Demoulin JB. FOXO transcription factors in cancer development and therapy. Cell Mol Life Sci 2016;73:1159-72.

8. Brunet A, Bonni A, Zigmond MJ, et al. Akt promotes cell survival by phosphorylating and inhibiting a Forkhead transcription factor. Cell 1999;96:857-68.

9. Kops GJ, Medema RH, Glassford J, et al. Control of cell cycle exit and entry by protein kinase B-regulated forkhead transcription factors. Mol Cell Biol 2002;22:2025-36.

10. Hu C, Ni Z, Li BS, et al. hTERT promotes the invasion of gastric cancer cells by enhancing FOXO3a ubiquitination and subsequent ITGB1 upregulation. Gut 2017;66:31-42.

11. Hou Y, Sun G, Jiang X, et al. Nuclear forkhead box O3a accumulation contributing to the proliferative suppression in liver cancer cells by PI3K/Akt signaling pathway. J Cancer Res Ther 2018;14:S1124-S8.

12. Guo S, Sonenshein GE. Forkhead box transcription factor FOXO3a regulates estrogen receptor alpha expression and is repressed by the Her-2/neu/phosphatidylinositol 3-kinase/Akt signaling pathway. Mol Cell Biol 2004;24:8681-90.

13. Wang X, Zeng Q, Li Z, et al. Adjudin synergizes with paclitaxel and inhibits cell growth and metastasis by regulating the sirtuin 3-Forkhead box O3a axis in human small-cell lung cancer. Thorac Cancer 2019;10:642-58.

14. Schito L, Semenza GL. Hypoxia-Inducible Factors: Master Regulators of Cancer Progression. Trends Cancer 2016;2:758-70.

15. Deng SJ, Chen HY, Ye Z, et al. Hypoxia-induced LncRNA-BX111 promotes metastasis and progression of pancreatic cancer through regulating ZEB1 transcription. Oncogene 2018;37:5811-28.

16. Hyun SW, Jung YS. Hypoxia induces FoxO3a-mediated dysfunction of blood-brain barrier. Biochem Biophys Res Commun 2014;450:1638-42.

17. Liang C, Dong Z, Cai X, et al. Hypoxia induces sorafenib resistance mediated by autophagy via activating FOXO3a in hepatocellular carcinoma. Cell Death Dis 2020;11:1017.

18. Harris AL. Hypoxia---a key regulatory factor in tumour growth. Nat Rev Cancer 2002;2:38-47.

19. Peng PH, Chieh-Yu Lai J, Hsu KW, et al. Hypoxia-induced lncRNA RP11-390F4.3 promotes epithelial-mesenchymal transition (EMT) and metastasis through upregulating EMT regulators. Cancer Lett 2020;483:35-45.
20. Williamson J, Hughes CM, Burke G, et al. A combined gamma-H2AX and 53BP1 approach to determine the DNA damage-repair response to exercise in hypoxia. Free Radic Biol Med 2020;154:9-17.

21. Liu J, Gao L, Zhan N, et al. Hypoxia induced ferritin light chain (FTL) promoted epithelia mesenchymal transition and chemoresistance of glioma. J Exp Clin Cancer Res 2020;39:137.

22. Torrisi F, Vicario N, Spitale FM, et al. The Role of Hypoxia and SRC Tyrosine Kinase in Glioblastoma Invasiveness and Radioresistance. Cancers (Basel) 2020;12:2860.

23. Seo J, Jeong DW, Park JW, et al. Fatty-acid-induced FABP5/HIF-1 reprograms lipid metabolism and enhances the proliferation of liver cancer cells. Commun Biol 2020;3:638.

24. Zhang $\mathrm{Y}$, Jiang L, Qin N, et al. hCINAP is potentially a direct target gene of HIF-1 and is required for hypoxiainduced EMT and apoptosis in cervical cancer cells. Biochem Cell Biol 2021;99:203-13.

25. Tong Q, Weaver MR, Kosmacek EA, et al. MnTE-2$\mathrm{PyP}$ reduces prostate cancer growth and metastasis by suppressing p300 activity and p300/HIF-1/CREB binding to the promoter region of the PAI-1 gene. Free Radic Biol Med 2016;94:185-94.

26. Qiang J, He J, Tao YF, et al. Hypoxia-induced miR92a regulates p53 signaling pathway and apoptosis by targeting calcium-sensing receptor in genetically improved farmed tilapia (Oreochromis niloticus). PLoS One 2020;15:e0238897.

27. Gilkes DM, Semenza GL, Wirtz D. Hypoxia and the extracellular matrix: drivers of tumour metastasis. Nat Rev Cancer 2014;14:430-9.

28. Zhang K, Yang Y, Ge H, et al. Artesunate promotes the proliferation of neural stem/progenitor cells and alleviates Ischemia-reperfusion Injury through PI3K/Akt/FOXO3a/p27(kip1) signaling pathway. Aging (Albany NY) 2020;12:8029-48.

29. Luo H, Hao E, Tan D, et al. Apoptosis effect of Aegiceras corniculatum on human colorectal cancer via activation of FoxO signaling pathway. Food Chem Toxicol 2019;134:110861.

30. Tanaka T, Iino M. Knockdown of Sec8 promotes cell-cycle arrest at G1/S phase by inducing p21 via control of FOXO proteins. FEBS J 2014;281:1068-84.

31. Mahmoud AR, Ali FEM, Abd-Elhamid TH, et al. Coenzyme Q10 protects hepatocytes from ischemia reperfusion-induced apoptosis and oxidative stress via 
regulation of Bax/Bcl-2/PUMA and Nrf-2/FOXO-3/Sirt1 signaling pathways. Tissue Cell 2019;60:1-13.

32. Yao LZ, Zhu YL, Liu JJ. Inhibition of PTEN Gene Expression by Small Interfering RNA on PI3K/Akt/FoxO3a Signaling Pathway in Human Nasopharyngeal Carcinoma. Technol Cancer Res Treat 2020;19:1533033820917959.

33. Ding D, Ao X, Li M, et al. FOXO3a-dependent Parkin regulates the development of gastric cancer by targeting ATP-binding cassette transporter E1. J Cell Physiol 2021;236:2740-55.

34. Kim DH, Jang JH, Kwon OS, et al. Nuclear Factor Erythroid-Derived 2-Like 2-Induced Reductive Stress Favors Self-Renewal of Breast Cancer Stem-Like Cells via the FoxO3a-Bmi-1 Axis. Antioxid Redox Signal 2020;32:1313-29.

35. Wu Y, Du H, Zhan M, et al. Sepiapterin reductase promotes hepatocellular carcinoma progression via

Cite this article as: Zhao H, Chen W, Zhu Y, Lou J. Hypoxia promotes pancreatic cancer cell migration, invasion, and epithelial-mesenchymal transition via modulating the FOXO3a/ DUSP6/ERK axis. J Gastrointest Oncol 2021;12(4):1691-1703. doi: 10.21037/jgo-21-359
FoxO3a/Bim signaling in a nonenzymatic manner. Cell Death Dis 2020;11:248.

36. Yang N, Zhang Q, Bi XJ. MiRNA-96 accelerates the malignant progression of ovarian cancer via targeting FOXO3a. Eur Rev Med Pharmacol Sci 2020;24:65-73.

37. Lyu X, Zeng L, Zhang H, et al. Hydroxychloroquine suppresses lung tumorigenesis via inducing FoxO3a nuclear translocation through STAT3 inactivation. Life Sci 2020;246:117366.

38. Liang C, Pang L, Ke Y, et al. LncRNA GAS6-AS2 facilitates tumor growth and metastasis of hepatocellular carcinoma by activating the PI3K/AKT/FoxO3a signaling pathway. Int J Clin Exp Pathol 2019;12:4011-23.

39. Tenbaum SP, Ordonez-Moran P, Puig I, et al. betacatenin confers resistance to PI3K and AKT inhibitors and subverts FOXO3a to promote metastasis in colon cancer. Nat Med 2012;18:892-901. 